\title{
Pediatric vasitis: A rare complication of epididymitis
}

\author{
Efrat Schurr, MD; Ruth Cytter-Kuint, MD; ${ }^{\dagger}$ Matityahu Ehrlichman, MD;* Giora Weiser, MD*
}

`Pediatric Department, Shaare Zedek Medical Center, Jerusalem, Israel; †Radiology Department, Shaare Zedek Medical Center, Jerusalem, Israel

Cite as: Can Urol Assoc J 2014;8(5-6):e436-8. http://dx.doi.org/10.5489/cuaj.1892 Published online June 19, 2014.

\section{Abstract}

Vasitis represents an inflammation of the vas deferens. This is a rare entity seen mostly in adult males following local surgery (e.g., vasectomy, hernia repair). Children with groin masses have a wide differential diagnosis. We describe a child with a groin mass following epididymitis diagnosed with vasitis and review the known literature regarding diagnostic tools and treatment. Vasitis in children, although rare, can be seen as a complication of epididymitis.

\section{Introduction}

Vasitis is a rare condition that constitutes an inflammatory process of the vas deferens. It has been described in adult patients, mainly following vasectomy (vasitis nodosa). In the pediatric population, this condition is rare and has only been reported twice in children with undiagnosed urological abnormalities.

We present a case of a 6-year-old boy with vasitis as a complication of epididymitis with no known urogenitary abnormalities. We discuss known etiologies and treatment, as well as the difficulties with imaging diagnosis.

\section{Case report}

A healthy 6-year-old boy presented to the Shaare-Zedek Medical Center Pediatric Emergency Department (ED) in Jerusalem, Israel. He had 24-hour history of a painful, swollen, erythematous left testis. Physical examination revealed a swollen and tender left scrotum. Ultrasonography of the testes ruled out testicular torsion and demonstrated an enlarged left epididymis with increased vascular flow (Fig. 1). The patient was discharged with symptomatic treatment (ibuprofen) following a normal urinalysis.

Three days later, the patient was admitted again to the
ED complaining of worsening pain and swelling in his left groin. Physical examination revealed edema and tenderness of his left groin, with a consistent tenderness in his left testis.

Repeated ultrasonography of his left groin showed enlarged lymph nodes, suggestive of left groin lymphadenitis. A urology consult recommended treatment with 7 days of oral antibiotics. This was with only partial regression of the swelling. A repeat urinalysis was negative.

Failing to respond to oral antibiotics, he was admitted to the pediatric ward with intravenous antibiotics. An additional ultrasound of his groin raised the suspicion of an inguinal hernia containing adipose tissue. There were no clinical signs or ultrasonographic findings suspicious of incarceration. As there seemed to be no compromise to either the testes or the intestines, both the pediatric urology and surgery teams decided he would be managed medically.

A computerized tomography (CT) scan to assess the extent of the suspected omental inguinal hernia was negative for an inguinal hernia. The CT instead revealed an inflamed spermatic cord. Given the patient's history of epididymitis, this swelling was consistent with vasitis (Fig. 2, Fig. 3). He was discharged with oral antibiotics and followed up at the pediatric urology clinic where the swelling has completely resolved.

\section{Discussion}

Vasitis in children is a rarely described entity. In fact, a review of the literature shows that only 2 previous cases have been described in children. ${ }^{1}$

Vasitis is an inflammatory process involving the vas deferens. As mentioned earlier, it is mostly described in adults following vasectomy in a form known as Vasitis nodosa. ${ }^{2}$ Previous reviews showed this to be predominantly an "adult" disease. ${ }^{3,4}$ The more rare form of vasitis, known as infectious vasitis, is considered to be secondary to a local spread of urogenital pathogens (i.e., Escherichia coli and Hemophilus influenza) from common infectious processes, such as epididymitis and orchitis. ${ }^{3}$ Rare pathogens, such as brucella and 


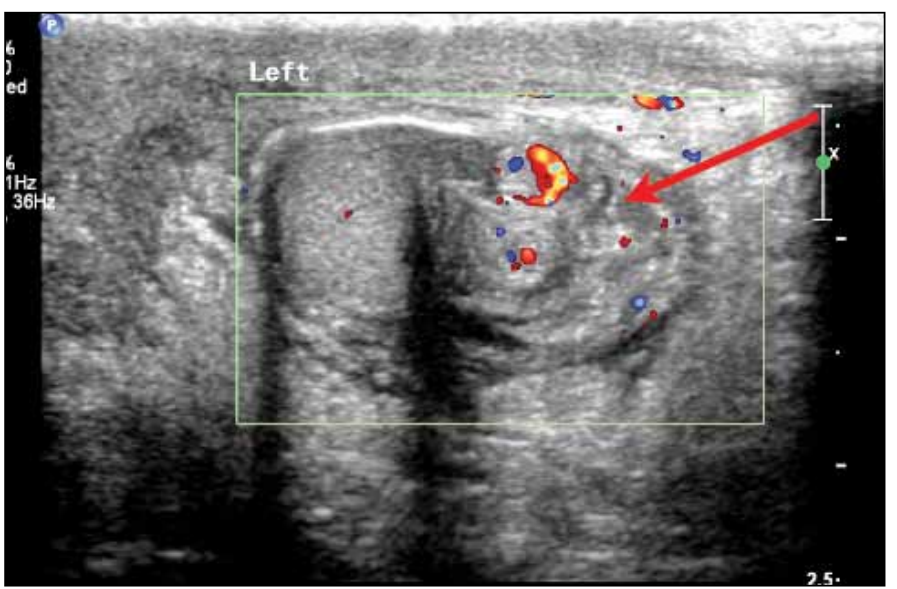

Fig. 1. Colour Doppler ultrasound scan of left testis revealing an enlarged, heterogeneous and hyperemic epididymis (arrow).

tuberculosis, have been described as well. ${ }^{5,6}$ It is important to point out that the actual pathogen has rarely been isolated. The treatment of vasitis is similar to other urogenital infections (i.e., antibiotics).

The diagnosis of vasitis is complicated both by its rarity and by its unclear ultrasonographic findings. The inflammatory mass is often confused with inguinal hernias or other spermatic cord tumours. In many cases, the diagnosis has only been made following surgery. In the past few years, several authors have recommended using CT to confirm the diagnosis. ${ }^{2,7}$

In this case, the ultrasonography ruled out lymphadenitis and an abscess. It did not, however, rule out a small abdominal wall defect. Since a heterogenous hyperechoic mass was seen, another imaging modality was needed to better characterize the finding.

A CT is considered the best available imaging tool for abdominal hernias. ${ }^{1}$ It is used often for this purpose and there are many descriptions of inguinal hernia findings in the literature. ${ }^{6}$ The major disadvantage with $\mathrm{CT}$ is the accompanying radiation, but it has multiple advantages, such as high resolution, short scanning time and availability.

The CT showed inflammation along the spermatic cord in our patient with history of epididymitis. A literature search led us to assume that it might have been vasitis. ${ }^{8}$ Although the spermatic cord contains also blood vessels, lymph, nerves and the tunica vaginalis, an inflammatory process of these structures is even less reasonable than vasitis considering the history (epididymitis) of the patient. His complete resolution is also indicative that this was indeed the final diagnosis.

In the pediatric population, this diagnosis is even rarer. To our knowledge, the only other description is by Muraoka and colleagues. These authors reported on 2 cases with congenital urogenital abnormalities that may have contributed to the children's susceptibility to an inflammatory reaction. ${ }^{8}$

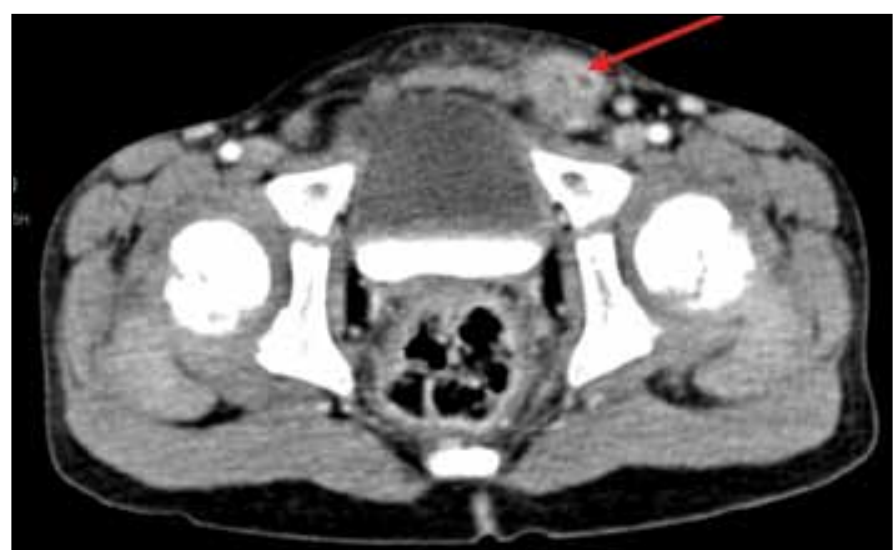

Fig. 2. Axial computed tomography image showing heterogeneous enhancing mass in the left inguinal region (arrow) with stranding of the surrounding fat as compared to the normal right spermatic cord.

The current vasitis case is unique in being a complication of epididymitis in a child with no abnormality. It is interesting that he indeed presented with the differential diagnosis of an inguinal hernia as mentioned in other studies. Although he was diagnosed with epididymitis, repeat urinalysis was negative. No cultures were sent, so no pathogens were identified.

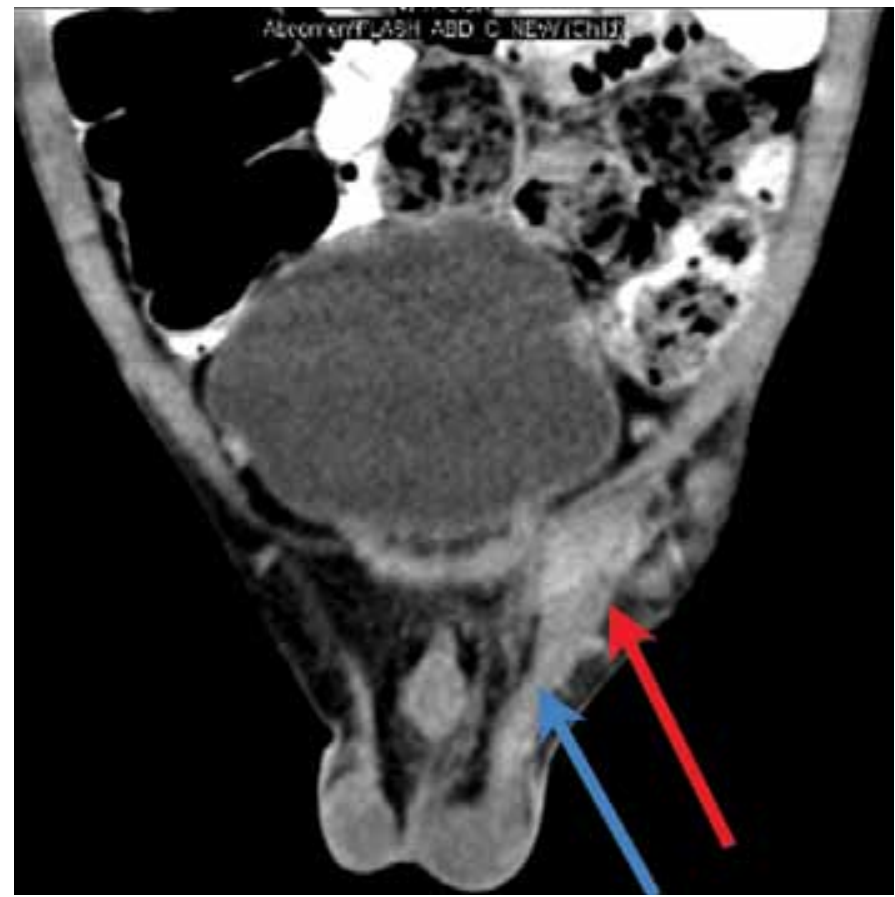

Fig. 3. Coronal reformat showing thickening and enhancement of the left spermatic cord (blue arrow). Heterogeneous inflammatory mass seen in the proximal cord (red arrow). No evidence of herniation from the peritoneal cavity. 
Schurr et al.

\section{Conclusion}

Although very rare, vasitis can present as a late complication of epididymitis in a previously healthy child and should be in the differential diagnosis of an inguinal mass complicating epididymitis. The use of CT in these cases may aid in avoiding unnecessary surgical intervention.

Competing interests: Dr. Schurr, Dr. Cytter-Kuint, Dr. Ehrlichman and Dr. Weiser declare no competing financial or personal interests.

This paper has been peer-reviewed.

\section{References}

1. Burkhardt JH, Arshanskiy Y, Munson JL, et al. Diagnosis of inguinal region hernias with axial CT: The lateral crescent sign and other key findings. Radiographics 2011;31:El-12. http://dx.doi.org/10.1148/ rg.312105129

2. Eddy K, Piercy B, Eddy R. Vasitis: Clinical and ultrasound confusion with inguinal hernia clarified by computed tomography. Can Urol Assoc J 2011;5:E74-6. http://dx.doi.org/10.5489/cuaj.10116

3. Yang DM, Kim HC, Lee HL, et al. Sonographic findings of acute vasitis. J Ultrasound Med 2010;29:1711-5.

4. Claviio RI., Rose-Nussbaumer J, Turek PJ. Clinically symptomatic vasitis: Clinical correlations in a rare condition. Syst Biol Reprod Med 2010;56:445-9. htrp://dx.doi.org/10.3109/19396368.2010.519814

5. Ryan SP, Harte PJ. Suppurative inflammation of vas deferens: An unusual groin mass. Urology 1988;31:245-6. http://dx.doi.org/10.1016/0090-4295(88)90151-3

6. Aguirre DA, Santosa AC, Casola G, et al. Abdominal wall hernias: Imaging features, complications and diagnostic piffalls at multi-detector row CT. Radiographics 2005;25:1501-20. http://dx.doi.org/10.1148/ rg. 256055018

7. Wilson SR, Katz DS. Computed tomography demonstration of epididymitis with extension to vas deferens. Urology 2006;68:1339-40. http://dx.doi.org/10.1016/j.urology.2006.08.1083

8. Muraoka I, Ohno Y, Kanematsu T, et al. Acute scrotum caused by vasitis with abscess formation in children with lower urological anomalies. Urology 2010;76:49-52. http://dx.doi.org/10.1016/j. urology.2010.02.010

Correspondence: Dr. Giora Weiser, Pediatric Emergency Department, Shaare Zedek Medical Center, 12 Shmuel Bait st, Jerusalem Israel; gioraweiser@gmail.com 